\title{
A NOVA COMPETITIVIDADE DA INDÚSTRIA E O NOVO EMPRESARIADO uma hipótese de trabalho
}

Glauco Arbix

João Alberto De Negri

\begin{abstract}
Resumo: Este artigo defende a existência de indícios de que a atual competitividade da indústria brasileira estaria sustentada em uma nova visão empresarial, surgida no país após a abertura da economia. São cinco os indícios: as estratégias das empresas voltadas para inovação e diferenciação de produtos; as mudanças estruturais e organizacionais; adequação das firmas aos padrões internacionais, via inovação tecnológica; a melhoria proporcionada pela inovação no desempenho exportador das firmas; e a internacionalização das firmas com foco na inovação tecnológica.
\end{abstract}

Palavras-chave: Inovação tecnológica. Indústria brasileira.

Abstract: This paper argues that current competitiveness of the Brazilian Industry is supported by a new entrepreneurial view, which emerged after the opening up of the economy. The argument is based on five focal points: companies' strategy based on innovation and product differentiation; organizational restructuring; companies' efforts to fit international product patterns by technological innovation; innovation is improving export performance of the firms; firms that are basing their internationalization process on technological innovation.

Key words: Technological innovation. Brazilian industry.

$\mathrm{E}$ ste artigo objetiva construir uma hipótese de trabalho de que a atual competitividade da indústria brasileira estaria sustentada em uma nova visão empresarial, que tem surgido no país após a abertura da economia. São cinco os indícios verificados nas empresas e discutidos neste texto: as estratégias competitivas voltadas para inovação tecnológica e diferenciação de produtos; as mudanças estruturais e organizacionais; adequação a normas e padrões internacionais via inovação tecnológica; inovação vista como fundamental para o desempenho exportador; e internacionalização com foco na inovação tecnológica. A partir dos novos comportamentos competitivos encontrados na indústria brasileira e de características no âmbito da firma, este artigo procura destacar os elementos de uma nova visão empresarial brasileira, originada a partir do esgotamento do nacional-desenvolvimentismo.
Não é recente a análise de que o modelo de crescimento e industrialização do Brasil, via substituição de importação, criou um viés pró-mercado interno, negligenciando o desempenho das empresas brasileiras no mercado internacional, por parte tanto do setor privado quanto do público. Se, por um lado, este modelo levado a cabo no pós-guerra consolidou uma indústria relativamente articulada, densa e com fornecedores locais, por outro, a proteção à concorrência internacional e $\mathrm{o}$ aparato produtivo estatal teriam sido responsáveis também por criar uma visão empresarial relativamente acomodada e passiva diante das principais tendências internacionais. Esta relativa acomodação teria distanciado as empresas industriais brasileiras dos padrões modernos de competição do mercado internacional, basicamente guiados pela capacidade de realização de inovação tecnológica e diferenciação de produtos. 
Economias semelhantes à brasileira foram abertas ao comércio internacional e a participação do Estado na economia foi substancialmente reduzida. No caso brasileiro, a abertura, a eliminação de inúmeros instrumentos de incentivos à produção doméstica e as privatizações passaram a assumir papel central na estratégia de desenvolvimento da economia na década de 90. Já em meados dos anos 90, após o processo de abertura da economia e, de forma especialmente relevante partir da estabilização macroeconômica, o debate sobre a sustentabilidade do crescimento ganhou relevância especial. No centro deste debate está a visão do setor privado quanto à inserção externa da indústria brasileira.

Recentemente, as discussões sobre as políticas de incentivo à inovação tecnológica, em geral, e os estudos realizados para apoiar a elaboração das Diretrizes da Política Industrial Tecnológica e de Comércio Exterior PITCE têm trazido novas contribuições sobre inserção externa da indústria brasileira. Existem fortes evidências de que o caso brasileiro de reestruturação da indústria é singular, quando comparado com outras economias, pois o novo ambiente econômico, diferente de gerar uma especialização regressiva, estaria impulsionando uma nova visão empresarial a respeito das potencialidades do Brasil na economia mundial. Distanciando-se da recorrente passividade e tradicional dependência das iniciativas governamentais, parte do empresariado de hoje começa a se conformar como um segmento que se dispõe a enfrentar e a se equiparar às melhores práticas da concorrência internacional, particularmente aquelas associadas à inovação tecnológica, com profundas conseqüências para a modernização de suas empresas.

Nas próximas seções deste artigo estão detalhadas as evidências e sistematizados os indícios desse novo comportamento e configuração. A se confirmar essa hipótese, estar-se-ia praticamente diante de uma alteração estrutural do sistema socioprodutivo brasileiro.

\section{ESTRATÉGIAS COMPETITIVAS NA INDÚSTRIA BRASILEIRA}

Os resultados aqui apresentados fazem parte do Projeto Inovação e Padrões Tecnológicos na Indústria Brasileira (SALERNO; DE NEGRI, 2005) que foi coordenado pelo Instituto de Pesquisa Econômica Aplicada - Ipea para apoiar a elaboração da PITCE. A originalidade deste projeto é dupla: por um lado, os dados referem-se ao mais amplo conjunto de informações jamais reunido sobre a indústria brasileira; ${ }^{1}$ e, por outro, ao categorizar as empresas por estratégias competitivas, tornou-se possível mapear e discutir com muito mais acuidade o patamar competitivo da indústria, possibilitando diagnóstico preciso para apoio à política industrial.

Para categorização das empresas, tomou-se por base a literatura econômica que demonstra que a inovação é uma estratégia que possibilita às empresas auferirem maiores ganhos, particularmente se ocorrer diferenciação de produto que permita a obtenção de preço-prêmio pela empresa. $^{2}$ Do ponto de vista da estratégia de negócios, tal visão foi difundida por Porter (1980), que agrupa as estratégias de negócios em três categorias:

- concorrência por diferenciação;

- concorrência por preço, na qual os produtos são padronizados e o diferencial de uma empresa se dá pelo seu nível menor de custos;

- concorrência por nichos, que seria um caso particular da estratégia de diferenciação.

De acordo com essas análises, a estratégia de diferenciação de produto seria aquela mais promissora para a lucratividade da empresa, que estaria menos sujeita à concorrência via menores salários e jornadas de trabalho mais extensas, ou derivada de recursos naturais (commodities) muito sujeitos a flutuações de preços. Também é conhecido o esforço dos países desenvolvidos para elaborarem políticas de inovação tecnológica e de diferenciação de produtos, seja através de investimentos e incentivos diversos, seja por meio de regulamentação, como é o caso do sistema GSM e das denominações de origem.

A tipologia desenvolvida no âmbito do Projeto ${ }^{3}$ baseiase na lógica acima e, para a indústria brasileira, as estratégias de competição podem ser traduzidas, do ponto de vista empírico, na tipificação das firmas em três categorias:

- aquelas que inovam e diferenciam produtos, ou seja, empresas de maior conteúdo tecnológico que competem por diferenciação de produto, o que seria a estratégia competitiva mais promissora, concentrando a ponta mais dinâmica da indústria e tendendo a capturar parcela maior da renda gerada pela indústria;

- firmas especializadas em produtos padronizados, categoria que reúne empresas razoavelmente atualizadas do ponto de vista de certas características operacionais (fabricação e logística), mas defasadas no que se refere a outras armas modernas da competição (pesquisa e desenvolvimento, marketing, gerenciamento de marcas, etc.) e que competem basicamente por custo e preço; 
- aquelas que não diferenciam produto e têm produtividade menor, categoria que engloba empresas que oferecem produtos de qualidade inferior, não exportadoras, porém se mostram capazes de captar espaços no mercado, através de baixos preços e outras possíveis vantagens. ${ }^{4}$

\section{CARACTERÍSTICAS DAS FIRMAS SEGUNDO ESTRATÉGIAS COMPETITIVAS}

Segundo os dados do IBGE, existem na indústria brasileira aproximadamente 72 mil empresas com mais de dez empregados. De acordo com suas estratégias competitivas, na indústria brasileira existem 1.199 firmas que inovam e diferenciam produtos, 15.311 especializadas em produtos padronizados e outras 55.486 que não diferenciam e têm produtividade menor (Tabela 1).

É razoável que a maioria das empresas corresponda àquelas que não diferenciam e têm produtividade menor. Nesta categoria, estão incluídas empresas de médio e pequeno portes que oferecem produtos não diferenciados de qualidade menor e que concorrem via preços. A sua grande participação numérica não é refletida, entretanto, com a mesma intensidade quando o indicador é a participação no faturamento. Estas empresas respondem por apenas $11,5 \%$ do faturamento total da indústria brasileira. Já aquelas que inovam e diferenciam produtos, apesar de representarem numericamente apenas $1,7 \%$ da indústria brasileira, são responsáveis por $25,9 \%$ do faturamento industrial, enquanto as empresas especializadas em produtos padronizados detêm $62,6 \%$ do faturamento.

A escala de produção das empresas que inovam e diferenciam produtos é significativamente maior do que nas demais categorias. O faturamento médio deste grupo é de $\mathrm{R} \$ 135,5$ milhões, enquanto nas especializadas em produtos padronizados corresponde a $\mathrm{R} \$ 25,7$ milhões e naquelas que não diferenciam e têm produtividade menor a $\mathrm{R} \$ 1,3$ milhão. Apesar de haver um diferencial significativo entre o tamanho médio das empresas nas três categorias, as eficiências de escala daquelas que inovam e diferenciam produtos e das especializadas em produtos padronizados estão muito próximas, mas divergem das que não diferenciam e têm produtividade menor (DE NEGRI et al., 2005). Isto mostra que os rendimentos de escala das empresas desta última categoria são inferiores quando comparadas com as demais empresas e que uma parte da sua ineficiência está associada ao fato delas operarem em escala de produção menor do que as outras.

As variáveis relativas ao pessoal ocupado são relevantes para análise da estratégia competitiva das empresas. A remuneração média mensal do pessoal ocupado é de $\mathrm{R} \$ 1.254,64$ nas empresas que inovam e diferenciam produtos, $\mathrm{R} \$ 749,02$ nas especializadas em produtos padronizados e $\mathrm{R} \$ 431,15$ naquelas que não diferenciam e têm produtividade menor. A remuneração está associada às características da mão-de-obra. A escolaridade média do trabalhador nas firmas que inovam e diferenciam produtos é significativamente maior do que nas demais. Em média, o empregado destas empresas tem 9,13 anos de estudos, contra 7,64 nas especializadas em produtos padronizados e 6,89 nas que não diferenciam e têm produtividade menor. $\mathrm{O}$ tempo de permanência médio do trabalhador também é maior nas empresas que inovam e diferenciam produtos (54,09 meses), quando comparadas com as especializadas em produtos padronizados $(43,90$

TABELA 1

Empresas Industriais, por Características, segundo Estratégias Competitivas Brasil - 2000

\begin{tabular}{|c|c|c|c|c|c|c|}
\hline \multirow{2}{*}{ Estratégias Competitivas } & \multicolumn{2}{|c|}{ Empresas } & \multirow{2}{*}{$\begin{array}{c}\text { Faturamento } \\
\text { Médio } \\
\text { (em milhões de } R \$ \text { ) }\end{array}$} & \multirow{2}{*}{$\begin{array}{l}\text { Participação } \\
\text { no } \\
\text { Faturamento } \\
\text { (\%) }\end{array}$} & \multirow{2}{*}{$\begin{array}{c}\text { Remuneração } \\
\text { Média do } \\
\text { Pessoal } \\
\text { Ocupado (R\$/mês) }\end{array}$} & \multirow{2}{*}{$\begin{array}{c}\text { Prêmio Salarial } \\
\text { Resultante do Compor- } \\
\text { tamento Competitivo } \\
\text { da Firma }(\%)\end{array}$} \\
\hline & №s Abs. & $\%$ & & & & \\
\hline Total & 72.005 & 100,0 & & 100,0 & & \\
\hline $\begin{array}{l}\text { Inovam e } \\
\text { Diferenciam Produtos }\end{array}$ & 1.199 & 1,7 & 135,5 & 25,9 & $1.254,64$ & 23 \\
\hline $\begin{array}{l}\text { Especializadas em } \\
\text { Produtos Padronizados }\end{array}$ & 15.311 & 21,3 & 25,7 & 62,6 & 749,02 & 11 \\
\hline $\begin{array}{l}\text { Não Diferenciam e } \\
\text { Têm Produtividade Menor }\end{array}$ & 55.495 & 77,1 & 1,3 & 11,5 & 431,15 & 0 \\
\hline
\end{tabular}
IBGE, Secex/MDIC, Bacen e Rais/MTE. 
meses) e com as que não diferenciam e têm produtividade menor (35,41 meses em média).

Bahia e Arbache (2005) mostraram, que também existe um prêmio salarial pago pelas empresas, que se diferencia de acordo com as estratégias competitivas. Segundo estes autores, as empresas que inovam e diferenciam produtos remuneram os empregados $23 \%$ a mais do que aquelas que não diferenciam e têm produtividade menor e as especializadas em produtos padronizados oferecem um prêmio salarial $11 \%$ a mais em comparação a esta última categoria. Estas evidências mostram que empresas que competem por inovação e diferenciação de produto tendem a remunerar melhor a mão-de-obra ocupada, sugerindo que uma política de incentivo à inovação e diferenciação de produto pode ter efeitos positivos do ponto de vista dos salários.

\section{Inovação Tecnológica - 1998-2000}

A taxa de inovação na indústria brasileira é de 31,5\% considerando-se as empresas com dez ou mais pessoas ocupadas. A inovação de produto novo e processo novo para o mercado é, entretanto, muito menos freqüente entre as empresas, chegando a $4,1 \%$ e $2,8 \%$, respectivamente. A Tabela 2 apresenta o resultado do processo inovativo das empresas na indústria brasileira por categoria.

Entre as empresas que inovam e diferenciam produtos, $70,6 \%$ também realizaram inovações de processo, sendo que $35,7 \%$ o fizeram para o mercado doméstico. $\mathrm{O}$ porcentual alto de empresas que realizam inovações de produto e de processo, entre as que inovam e diferenciam produtos, parece indicar que a inovação de produto novo para o mercado exige também esforço de inovação em processo. O padrão de inovação tecnológica das empresas especializadas em produtos padronizados é diferente: $35,6 \%$ implementaram inovação de processo e $26,2 \%$ inovaram produtos. Comportamento semelhante, porém de menor intensidade, é encontrado nas empresas que não diferenciam e têm produtividade menor: $21,4 \%$ realizaram inovação de processo e 13,4\% inovaram produtos.

De forma geral, estes dados indicam que há um diferencial de padrão de inovação tecnológica das empresas que inovam e diferenciam produto quando comparadas com as demais. Nas especializadas em produtos padronizados e naquelas que não diferenciam e têm produtividade menor, o comportamento inovador é fortemente associado à difusão tecnológica, que é realizada de forma especialmente relevante por meio da inovação de processo. Uma parte significativa das inovações de processo é realizada através da introdução de máquinas e equipamentos, freqüentemente importadas. Nas empresas especializadas em produtos padronizados, o porcentual de inovadoras é maior do que nas que não diferenciam e têm produtividade menor, indicando uma preocupação maior nesta categoria com a eficiência produtiva (técnica e de escala). Neste último grupo, há um grande número de empresas, geralmente pequenas e médias, que não inovam e nem participam de processos de difusão tecnológica, compreendendo, via de regra, empresas defasadas tanto do ponto de vista tecnológico como de eficiência produtiva.

Os dados apresentados na Tabela 3 corroboram também as evidências de que a difusão de tecnologia domina o comportamento inovador das empresas especializadas em

TABELA 2

Taxas de Inovação de Produtos e Processo, segundo as Estratégias Competitivas das Empresas Brasil - 1998/2000

Em porcentagem

\begin{tabular}{|c|c|c|c|c|c|c|}
\hline \multirow[b]{2}{*}{ Estratégias Competitivas } & \multicolumn{3}{|c|}{ Inovadoras de Produto } & \multicolumn{3}{|c|}{ Inovadoras de Processo } \\
\hline & Total & $\begin{array}{l}\text { Novo para } \\
\text { Mercado }\end{array}$ & $\begin{array}{c}\text { Novo para } \\
\text { Empresa }\end{array}$ & Total & $\begin{array}{l}\text { Novo para } \\
\text { Mercado }\end{array}$ & $\begin{array}{c}\text { Novo para } \\
\text { Empresa }\end{array}$ \\
\hline Total & 17,6 & 4,1 & 14,4 & 25,2 & 2,8 & 23,3 \\
\hline Inovam e Diferenciam & & & & & & \\
\hline Produtos & 100,0 & 100,0 & 28,4 & 70,6 & 35,7 & 48,5 \\
\hline Especializadas em & & & & & & \\
\hline Produtos Padronizados & 26,2 & 4,5 & 23,1 & 35,6 & 5,7 & 31,6 \\
\hline Não Diferenciam e Têm & & & & & & \\
\hline Produtividade Menor & 13,4 & 1,9 & 11,7 & 21,4 & 1,3 & 20,4 \\
\hline
\end{tabular}

Fonte: IBGE. Pesquisa Industrial - Inovação Tecnológica - Pintec 2000. Elaboração: Ipea/Diset a partir da transformação dos dados obtidos na fonte e com a incorporação de dados da PIA/IBGE, Secex/MDIC, Bacen e Rais/MTE.

Nota: Porcentuais por categoria de estratégia competitiva. Como a empresa pode inovar simultaneamente em produto e processo novos para a empresa ou para o mercado, os valores não somam $100 \%$. 
produtos padronizados e daquelas que não diferenciam e têm produtividade menor. Quando se observa a informação sobre quem é o principal responsável pelas inovações, verifica-se que em $78 \%$ das empresas especializadas em produtos padronizados, o principal responsável pela inovação de processo foi outra empresa. Este valor sobe para $88,3 \%$ nas das empresas que não diferenciam e têm produtividade menor. Menos da metade $(47,5 \%)$ das inovações de processo é realizada por outra empresa no caso daquelas que inovam e diferenciam produtos. Mesmo no que se refere às inovações de produto, a difusão de tecnologia é maior nas empresas especializadas em produtos padronizados e nas que não diferenciam e têm produtividade menor, quando comparadas àquelas que inovam e diferenciam produtos.

A Tabela 3 também mostra que as empresas que inovam e diferenciam produtos apresentam, simultaneamente, a maior porcentagem de desenvolvimento próprio de processo (dentro da própria unidade) e a menor incidência de recurso a outras empresas. Ou seja, parece haver uma associação entre inovação e diferenciação de produto e inovação de processo, ainda que essa inovação possa ser via mudança de equipamento.

Faz parte também do esforço inovador a capacidade de as empresas estabelecerem alianças cooperativas e parcerias para a inovação tecnológica. As parcerias se diferem de acordo com o padrão de inovação das empresas. A despeito da diferença entre os padrões de inovação tecnológica, verifica-se que as empresas especializadas em produtos padronizados e as que não diferenciam e têm produtividade menor, quando realizam inovação de produto, o fazem com um esforço individual maior do que aquelas que inovam e diferenciam produtos, das quais $29,3 \%$ realizaram inovação de produto em conjunto com outra empresa do grupo empresarial ao qual pertencem ou então em cooperação com outras empresas. Já nas especializadas em produtos padronizados este porcentual é de $15,9 \%$ e naquelas que não diferenciam produto e têm produtividade menor corresponde a $6,4 \%$.

As empresas que inovam e diferenciam produtos também realizam gastos na aquisição de $P \& D$ externo e de conhecimento, em proporção ao faturamento, maiores do que nas demais categorias, o que corrobora as evidências de que estas empresas cooperam ou realizam inovações dentro do seu grupo empresarial. Não é trivial, entretanto, a relação de causalidade entre desempenho inovativo da empresa e cooperação. As empresas podem inovar e com isso ampliar o leque de cooperação/parceria e troca de informações com outras empresas que também inovam, ou então podem associar-se para alcançar uma inovação tecnológica pretendida.

Um dos indicadores de esforço individual das empresas que realizam inovação são os gastos de P\&D interno como proporção do faturamento. Considerando apenas as empresas inovadoras em cada categoria, a média de gastos de P\&D interno sobre o faturamento para aquelas que inovam e diferenciam produtos é de 3,06\%, enquanto para as especializadas em produtos padronizados este porcentual é de $2,03 \%$ e naquelas que não diferenciam e têm produtividade menor corresponde a $1,36 \%$.

O esforço da empresa para realizar inovação tecnológica tem como objetivo aumentar os recursos e potencialidades

TABELA 3

Empresas, por Principal Responsável pela Inovação, segundo Estratégias Competitivas Brasil - 1998-2000

\begin{tabular}{|c|c|c|c|c|}
\hline & & & & Em porcentagem \\
\hline Estratégias Competitivas & Empresa & $\begin{array}{c}\text { Outra Empresa } \\
\text { do Grupo }\end{array}$ & $\begin{array}{l}\text { Empresa em } \\
\text { Cooperação }\end{array}$ & $\begin{array}{c}\text { Outras } \\
\text { Empresas }\end{array}$ \\
\hline Produto & 71,4 & 3,8 & 7,8 & 17,0 \\
\hline Inovam e Diferenciam Produtos & 65,6 & 17,0 & 12,3 & 5,0 \\
\hline Especializadas em Produtos Padronizados & 72,6 & 6,0 & 9,9 & 11,5 \\
\hline Não Diferenciam e têm Produtividade Menor & 71,6 & 0,5 & 5,9 & 21,9 \\
\hline Processo & 10,6 & 1,2 & 4,9 & 83,3 \\
\hline Inovam e Diferenciam Produtos & 30,7 & 6,6 & 15,2 & 47,5 \\
\hline Especializadas em Produtos Padronizados & 13,1 & 2,5 & 6,3 & 78,1 \\
\hline Não Diferenciam e têm Produtividade Menor & 8,1 & 0,1 & 3,5 & 88,3 \\
\hline
\end{tabular}

Fonte: IBGE. Pesquisa Industrial - Inovação Tecnológica - Pintec 2000. Elaboração: Ipea/Diset a partir da transformação dos dados obtidos na fonte e com a incorporação de dados da PIA/IBGE, Secex/MDIC, Bacen e Rais/MTE. 
disponíveis no seu interior e, com isso, obter vantagens competitivas que se traduzem em rentabilidade superior à de seus competidores. O impacto da inovação tecnológica em termos de recursos e potencialidades pode ser visto na Tabela 4, que apresenta a proporção de empresas que atribuíram alta importância a impactos específicos do processo de inovação.

Naquelas que inovam e diferenciam produtos, a inovação tem um impacto maior na melhoria da qualidade $\mathrm{e}$ na ampliação da gama dos produtos ofertados. De fato, um dos ativos importantes desta categoria, em comparação às demais, é a sua potencialidade de diferenciar e melhorar a qualidade do seu produto. Das empresas que inovam e diferenciam produtos, $46,8 \%$ atribuíram alta importância da inovação tecnológica para ampliação da gama de produtos ofertados, sendo que, para as demais categorias, este valor é significativamente menor. A estratégia de direcionar os recursos disponíveis na empresa para gerar inovações que aumentem as potencialidades de diferenciar e melhorar a qualidade do produto ofertado se reflete no seu posicionamento no mercado. O por- centual de empresas que atribuíram alta importância da inovação tecnológica para manutenção, ampliação e abertura de novos mercados é maior naquelas que inovam e diferenciam produtos do que nas outras duas categorias.

Já a proporção de empresas que atribuíram alta importância ao aumento da capacidade produtiva e da flexibilidade de produção é maior nas especializadas em produtos padronizados e nas que não diferenciam e têm produtividade menor. Estas empresas, produtoras de bens menos diferenciados, tendem a direcionar seus recursos disponíveis para ampliar suas potencialidades fabris, procurando fazer o mesmo produto da melhor forma. É por isso que grande parte da inovação realizada por estas empresas refere-se a processo. De forma geral, são menores os porcentuais de empresas que atribuíram alta importância da inovação tecnológica para a redução de custos do trabalho, de consumo de matérias-primas e de energia elétrica e parece não haver grandes diferenças na comparação entre as categorias.

Um dado especialmente relevante que deve ser observado na Tabela 4 é que 23,1\% das empresas que inovam e

TABELA 4

Proporção de Empresas Inovadoras que Atribuíram Alta Importância da Inovação sobre Aspectos Específicos, Segundo Estratégias Competitivas

Brasil - 1998/2000

Em porcentagem

\begin{tabular}{|c|c|c|c|}
\hline Estratégias Competitivas & $\begin{array}{c}\text { Inovam e } \\
\text { Diferenciam Produtos }\end{array}$ & $\begin{array}{c}\text { Especializadas em } \\
\text { Produtos Padronizados }\end{array}$ & $\begin{array}{c}\text { Não Diferenciam e } \\
\text { têm Produtividade Menor }\end{array}$ \\
\hline \multicolumn{4}{|l|}{ Produto } \\
\hline Melhorou a Qualidade dos Produtos & 61,2 & 57,1 & 55,6 \\
\hline Ampliou a Gama de Produtos Ofertados & 46,8 & 28,7 & 24,0 \\
\hline \multicolumn{4}{|l|}{ Mercado } \\
\hline Permitiu Manter a Participação no Mercado & 55,8 & 50,6 & 47,7 \\
\hline Ampliou a Participação no Mercado & 47,5 & 39,9 & 34,6 \\
\hline \multicolumn{4}{|l|}{ Processo } \\
\hline Permitiu Abrir Novos Mercados & 34,9 & 23,7 & 21,0 \\
\hline Aumentou a Capacidade Produtiva & 34,1 & 42,5 & 43,6 \\
\hline Aumentou a Flexibilidade da Produção & 32,7 & 36,7 & 34,6 \\
\hline Reduziu os Custos do Trabalho & 23,7 & 24,2 & 22,3 \\
\hline Reduziu o Consumo de Matérias-Primas & 10,6 & 9,2 & 7,2 \\
\hline Reduziu o Consumo de Energia & 8,8 & 9,0 & 8,3 \\
\hline \multicolumn{4}{|l|}{ Outros Impactos } \\
\hline Reduziu Impacto no Meio Ambiente & 28,8 & 27,4 & 22,2 \\
\hline Enquadramento nas Normas do Mercado Interno & 32,9 & 23,0 & 15,9 \\
\hline Enquadramento nas Normas do Mercado Externo & 23,1 & 13,2 & 1,8 \\
\hline
\end{tabular}

Fonte: IBGE. Pesquisa Industrial - Inovação Tecnológica - Pintec 2000. Elaboração: Ipea/Diset a partir da transformação dos dados obtidos na fonte e com a incorporação de dados da PIA/IBGE, Secex/MDIC, Bacen e Rais/MTE. 
diferenciam produtos atribuíram alta importância da inovação para o enquadramento às normas do mercado externo. Nas especializadas em produtos padronizados este porcentual é de $13,2 \%$.

Uma das potencialidades importantes para o processo de competição das empresas é sua capacidade de promover mudanças microeconômicas relativas a suas estratégias de mercado e também organizacionais. Não existe relação de causalidade bem definida entre estas mudanças e a inovação tecnológica. Ao mesmo tempo em que impulsiona o processo de mudança, a inovação tecnológica impulsionada por ele. A Tabela 5 apresenta os dados referentes às empresas inovadoras que declararam realizar mudanças estratégias e organizacionais.

Naquelas que inovam e diferenciam produtos, $39,1 \%$ declararam que realizaram mudanças na estratégia corporativa, que correspondem a alterações de produto e/ou mercado de atuação das empresas. As inovadoras de produto novo para o mercado são de fato empresas mais agressivas, não apenas no lançamento de novos produtos, mas também na conquista de novos mercados. Mais de 50\% destas firmas também realizaram mudanças na gestão, estrutura organizacional, marketing e gerenciamento. Nas demais categorias, esta proporção é menor. As mudanças na estética, desenho, etc. do produto são mais simples de serem implementadas e, por isso, grande parte das empresas, independentemente da categoria, realizou estas alterações.

\section{INSERÇÃO NO COMÉRCIO EXTERIOR}

As empresas que inovam e diferenciam produtos exportam e importam em média muito mais do que as demais empresas exportadoras. A Tabela 6 apresenta indi- cadores de inserção das empresas industriais brasileiras no comércio internacional. O coeficiente de exportação médio das especializadas em produtos padronizados é praticamente o dobro das demais inseridas no comércio internacional e o coeficiente de importação médio é 50\% maior nestas empresas quando comparado com outras.

A literatura sobre os determinantes do comércio internacional afirma que as exportações podem, por um lado, estar relacionadas às tradicionais vantagens comparativas que são determinadas pela dotação relativa de fatores de produção, como mão-de-obra e recursos naturais, e são associadas ao comércio interindústria. Por outro lado, as exportações podem estar baseadas em economias de escala, inovação tecnológica e diferenciação de produto e, neste caso, estariam essencialmente associadas ao comércio intra-indústria. O Brasil é um país em desenvolvimento onde a abundância em recursos naturais e mão-de-obra o torna competitivo nas exportações de bens que demandam maior dotação relativa destes fatores, mas o tamanho do mercado doméstico brasileiro e o esforço inovativo das empresas no Brasil também tornam o país competitivo em determinados segmentos em que inovação tecnológica e escala de produção são determinantes da competitividade das empresas no mercado internacional.

Os indicadores de comércio exterior sinalizam padrão muito diferente entre as empresas que inovam e diferenciam produtos e as especializadas em produtos padronizados. As primeiras obtêm melhor preço no mercado internacional quando comparadas às demais exportadoras brasileiras, demandando mais importações de componentes ou produtos complementares às linhas de produção doméstica. Isto ocorre porque o Brasil é parcialmente ou não competitivo em segmentos de maior intensidade

TABELA 5

Proporção de Empresas Inovadoras que Implementaram Mudanças Estratégicas e Organizacionais, segundo Estratégias Competitivas Brasil - 1998/2000

\begin{tabular}{|c|c|c|c|c|c|c|}
\hline & & & & & & Em porcentagem \\
\hline Estratégias Competitivas & $\begin{array}{c}\text { Mudanças na } \\
\text { Estratégia } \\
\text { Corporativa }\end{array}$ & $\begin{array}{c}\text { Técnicas } \\
\text { Avançadas de } \\
\text { Gestão }\end{array}$ & $\begin{array}{c}\text { Mudanças na } \\
\text { Estrutura } \\
\text { Organizacional }\end{array}$ & $\begin{array}{c}\text { Mudanças de } \\
\text { Estratégias de } \\
\text { Marketing }\end{array}$ & $\begin{array}{c}\text { Mudança na } \\
\text { Estética, } \\
\text { Desenho, etc. }\end{array}$ & $\begin{array}{c}\text { Novos } \\
\text { Métodos de } \\
\text { Gerenciamento }\end{array}$ \\
\hline
\end{tabular}

Inovam e Diferenciam

Produtos
39,1

26,8

18,6
56,0

42,6

28,1
51,8

44,0

36,0
52,7

44,5

38,5
72,9

66,4

68,0
54,3

Produtividade Menor

Fonte: IBGE. Pesquisa Industrial - Inovação Tecnológica - Pintec 2000. Elaboração: Ipea/Diset a partir da transformação dos dados obtidos na fonte e com a incorporação de dados da PIA/IBGE, Secex/MDIC, Bacen e Rais/MTE. 
TABELA 6

Exportações, Importações e Coeficientes, segundo Estratégias Competitivas das Empresas Brasil - 2000 (1)

\begin{tabular}{|c|c|c|c|c|}
\hline Estratégias Competitivas & $\begin{array}{l}\text { Exportações } \\
\text { (US\$ milhões) }\end{array}$ & $\begin{array}{l}\text { Importações } \\
\text { (US\$ milhões) }\end{array}$ & $\begin{array}{c}\text { Coeficiente de } \\
\text { Exportação (2) } \\
(\%)\end{array}$ & $\begin{array}{c}\text { Coeficiente de } \\
\text { Importação (3) } \\
(\%)\end{array}$ \\
\hline Inovam e Diferenciam Produtos & 11,4 & 12,01 & 0,11 & 0,15 \\
\hline Especializadas em Produtos Padronizados & 2,1 & 1,8 & 0,21 & 0,10 \\
\hline Não Diferenciam e Têm Produtividade Menor & 0,0 & 0,0024 & 0,00 & 0,01 \\
\hline
\end{tabular}

Fonte: IBGE. Pesquisa Industrial - Inovação Tecnológica - Pintec 2000. Elaboração: Ipea/Diset a partir da transformação dos dados obtidos na fonte e com a incorporação de dados da PIA/IBGE, Secex/MDIC, Bacen e Rais/MTE.

(1) Média no ano.

(2) Valor exportado $(R \$)$ sobre faturamento $(R \$)$

(3) Valor importado $(R \$)$ sobre faturamento $(R \$)$.

tecnológica. Estas empresas, para se manterem competitivas no mercado internacional, estariam importando componentes de maior conteúdo tecnológico para sua linha de produção, ao mesmo tempo em que complementam a linha de produtos oferecidos ao mercado doméstico. Desta maneira, as empresas que inovam e diferenciam produtos possuem um padrão de comércio intra-indústria, parte intra-empresa, caracterizado em grande medida pela complementaridade tecnológica com o exterior.

As especializadas em produtos padronizados, por produzirem e exportarem bens menos diferenciados, mais homogêneos e de menor conteúdo tecnológico, aproveitam de forma mais intensa a abundância na dotação relativa de fatores de produção, como mão-de-obra barata e recursos naturais disponíveis no mercado brasileiro. Neste caso, as empresas são competitivas no comércio interindustrial com outros países. Este tipo de comércio depende menos de importações e as exportações realizadas pela firma acabam por contribuir com uma parcela maior do faturamento. Nesta categoria, as importações são realizadas com o objetivo de aproveitar a complementaridade intra-indústria baseada nos potenciais que são criados pela escala de produção doméstica.

De Negri e Freitas (2004) mostraram que a inovação tecnológica é um dos determinantes das exportações das empresas brasileiras. Este estudo aponta para duas evidências. A primeira é que uma firma que realiza inovação tecnológica tem $16 \%$ mais chances de ser exportadora do que outra que não faz inovação tecnológica. A segunda é que um aumento na propensão de a empresa realizar inovação tecnológica, mensurada através de um aumento em um ano de escolaridade média de seus trabalhadores, associado a uma expansão de $20 \%$ na eficiência de escala, possibilitaria que empresas que não realizam exportações passassem a exportar US\$ 559 mil por ano. Consideran- do que existem aproximadamente 18 mil firmas exportadoras na indústria brasileira, uma ampliação da base exportadora em torno de $14 \%$ (ou seja, se 2.500 empresas passassem a exportar como resultado do aumento de escala e da sua capacidade de inovar) seria responsável por um adicional de US\$ 1,4 bilhão de exportações anuais. Este valor seria equivalente ao impacto resultante da eliminação completa das barreiras tarifárias para o mercado dos Estados Unidos e Canadá no âmbito da Alca somado ao impacto da eliminação completa das barreiras tarifárias para a Europa, o que poderia ser realizado no âmbito das negociações Mercosul-Europa. ${ }^{5}$

\section{Internacionalização com Foco na Inovação Tecnológica}

Uma boa parte do comércio internacional se dá intraempresa e, desta forma, o desempenho exportador de um país pode ser influenciado positivamente quando suas empresas estabelecem subsidiárias no exterior, que podem contribuir com o desempenho exportador por exercerem diversas funções, tais como acessar canais de comercialização, adaptar os produtos à demanda de mercados específicos, criar mercados, acessar recursos financeiros mais baratos, apropriar tecnologias não disponíveis no mercado doméstico, etc.

Arbix, Salerno e De Negri (2004; 2005a) mostraram que os processos de internacionalização com foco na inovação tecnológica afetam positivamente o desempenho exportador das empresas. Verificou-se que as empresas internacionalizadas com foco na inovação remuneram melhor a mão-de-obra, empregam pessoal com maior escolaridade e, portanto, geram empregos de melhor qualidade. Além disso, apresentam maior porcentual de dispêndio em treinamento de mão-de-obra relativamente ao faturamento, 
o que impulsionaria de alguma forma a qualificação da mãode-obra doméstica. Com relação às características da empresa, observou-se que aquelas internacionalizadas com foco na inovação exportam mais do que as que não fazem este tipo de internacionalização. Portanto, há evidências de que o aumento da competitividade das empresas é influenciado positivamente pelas inovações tecnológicas que são resultantes do processo de internacionalização. Os autores realçaram também o elo de ligação entre a inovação tecnológica, a internacionalização das empresas industriais brasileiras via investimento direto externo e a obtenção de preço-prêmio nas exportações (ARBIX; SALERNO; DE NEGRI, 2005b). Segundo os autores, esse elo de ligação existe porque a inovação tecnológica produz ativos específicos que possibilitam e facilitam a internacionalização das empresas, o que, por sua vez, contribui positivamente para a obtenção de um preço-prêmio nas exportações. Em um mecanismo de retroalimentação, a internacionalização favorece a inovação e a inovação aumenta a possibilidade de obtenção de preços-prêmio em relação aos demais exportadores.

\section{CONCLUSÕES}

Este artigo procurou destacar e sistematizar alguns sinais indicadores da nova competitividade da indústria brasileira, cujo suporte básico seria um novo comportamento e visão empresarial.

O primeiro indício relevante é que a inovação tecnológica e a diferenciação de produtos fazem parte das estratégias competitivas de um conjunto de empresas que representam $25,9 \%$ do faturamento da indústria brasileira. Aquelas que inovam e diferenciam produtos pagam prêmio salarial de $23 \%$, empregam mão-de-obra mais qualificada e o pessoal ocupado permanece mais tempo no emprego. Estes indicadores mostram que estas empresas valorizam o capital humano e o conteúdo tecnológico obtido através do aprendizado em seu interior. Estas empresas realizam inovação de produto novo para o mercado e 70,6\% realizam também inovação de processo, o que indica um padrão de inovação tecnológica mais sofisticado e que não é guiado apenas pela difusão de tecnologias já existentes. O grande número de parcerias e alianças cooperativas realizadas pelas empresas que inovam e diferenciam produtos indica que estas são capazes de empreender esforços articulados para alcançar a inovação tecnológica.

O segundo indício apontado mostra que, nas empresas que inovam e diferenciam produtos, 39,1\% declara- ram que realizaram mudanças na estratégia corporativa, ou seja, àquelas relacionadas com alterações de produto e/ou mercado de atuação. As empresas inovadoras de produto novo para o mercado são agressivas não apenas no lançamento de novos produtos, mas também na conquista de novos mercados. Mais de 50\% destas empresas também realizaram mudanças na gestão, estrutura organizacional, marketing e gerenciamento. Esta é uma das características microeconômica marcantes do processo pró-ativo de reestruturação das empresas após a abertura econômica.

O terceiro indício mostra que $23,1 \%$ das empresas que inovam e diferenciam produtos e $13,2 \%$ das especializadas em produtos padronizados realizaram inovação para se adequarem às normas e padrões internacionais. Estes números são importantes porque podem estar demonstrando que há uma parcela não desprezível de firmas na indústria brasileira voltada para atender ao mercado externo, devendo, portanto, considerar o mercado externo dentro da estratégia da empresa. Estes números são especialmente relevantes no contexto atual, porque no passado cristalizou-se no Brasil a interpretação de que o processo de desenvolvimento industrial brasileiro teria sido voltado para dentro e que as empresas enxergariam sua inserção internacional como uma parte residual de sua estratégia de crescimento, que ganharia importância somente nos momentos de restrições no mercado interno. O porcentual não desprezível de empresas que realizaram uma atividade nobre e singular do ponto de vista da competição, a inovação tecnológica, para se adequarem ao mercado internacional sugere que algo de novo na visão empresarial brasileira estaria ocorrendo.

O quarto indício diz respeito à importância da inovação tecnológica nas exportações brasileiras. A firma que realiza inovação tecnológica tem $16 \%$ mais chances de ser exportadora do que outra que não faz inovação tecnológica. Isso indica que o empresariado brasileiro tem identificado a inovação tecnológica como um passo importante para sua inserção no comércio internacional. Neste sentido, o Brasil é um país em desenvolvimento onde a abundância em recursos naturais e mão-de-obra o torna competitivo nas exportações de bens que demandam maior dotação relativa destes fatores, mas o tamanho do mercado doméstico brasileiro e o esforço inovativo das firmas no Brasil também tornam o país competitivo em determinados segmentos em que inovação tecnológica e escala de produção são determinantes da competitividade das empresas no mercado internacional. 
O quinto indício está relacionado à internacionalização das empresas industriais brasileiras. Aquelas que inovam e diferenciam produtos têm buscado no exterior informações para realizar inovação tecnológica. A internacionalização com foco na inovação tecnológica produz impactos positivos sobre o desempenho exportador das empresas, pois aumenta não apenas o volume exportado, mas também o valor agregado aos bens exportados.

Os sinais reunidos neste trabalho dão consistência à hipótese de que a nova competitividade da indústria brasileira encontra sustentação em um novo empresariado. Um das características importantes da reestruturação da indústria após a abertura econômica e estabilização é que muitas empresas brasileiras estão desenvolvendo um comportamento pró-ativo, orientando-se pelas práticas mais nobres da competição: a inovação tecnológica e a diferenciação de produto. As informações coletadas e já processadas sugerem fortemente a necessidade de construção de uma nova agenda de pesquisa sobre os sistemas produtivos, que incorpore as dimensões regionais, setoriais e locais dos processos de inovação, assim como para seus desdobramentos em outros setores e campos da atividade econômica, para além da indústria em sentido estrito.

\section{NOTAS}

1. Foi utilizada base de dados organizada pelo Ipea, que reúne os dados da Pesquisa Industrial Anual (PIA) e da Pesquisa Industrial sobre Inovação Tecnológica (Pintec), do Instituto Brasileiro de Geografia e Estatística (IBGE), da Relação Anual de Informações Sociais (Rais) do Ministério do Trabalho e Emprego (MTE), da Secretaria de Comércio Exterior (Secex) do Ministério de Desenvolvimento Indústria e Comércio Exterior (MDIC), do Censo do Capital Estrangeiro do Banco Central (Bacen), do Registro de Capitais Brasileiros no Exterior (Bacen) e da Base de Dados de Compras Governamentais do Ministério do Planejamento, Orçamento e Gestão (MPOG). O banco de dados é composto por uma amostra de aproximadamente 70 mil empresas industriais e cinco milhões de pessoas que nelas trabalham. O Ipea não tem a posse física das informações utilizadas neste trabalho e, portanto, a realização de estudos como este só é possível devido às parcerias estabelecidas entre o Ipea, IBGE, MTE, Bacen, o MPOG e Secex/MDIC. $\mathrm{O}$ acesso às informações necessárias ao trabalho seguiu rigorosamente os procedimentos que garantem o sigilo de informações restritas.

2. É utilizada também a expressão "lucro de monopólio", no sentido de que a empresa obtém um ganho extra pelo fato de que, num determinado horizonte, seu produto se diferencia dos demais, criando uma situação similar a um monopólio de fato.

3. Com destaque para o professor Antônio Barros de Castro (IE/UFRJ), que teve a idéia inicial de categorizar as empresas por seu desempenho competitivo. Tal idéia foi aprofundada com os professores Afonso Fleury (Politécnica USP) e Adriano Proença (Coppe e EE-UFRJ).

4. Na indústria brasileira poderia, ainda, ser contemplado um quarto agrupamento de empresas, formado por aquelas de base tecnológica e que estão em fase inicial de operação ou em condições de deixar as incubadoras em que foram gestadas. Esta categoria não foi analisada no Projeto.

5. Ver De Negri, Arbache (2003) e De Negri, Arbache e Falcão Silva (2003).

\section{REFERÊNCIAS BIBLIOGRÁFICAS}

ARBIX, G.; SALERNO, M.S.; DE NEGRI, J.A. Internacionalização com foco na inovação tecnológica e seu impacto sobre as exportações das firmas brasileiras. Revista DADOS, 2005a. No prelo.

Padrões de internacionalização das firmas industriais brasileiras. In: SALERNO, M.S.; DE NEGRI, J.A. (Coord.). Inovação, padrões tecnológicos e desempenho das firmas industriais brasileiras. Brasília: Ipea, 2005b. No prelo.

Inovação, via internacionalização, faz bem para as exportações brasileiras. Economia do conhecimento e inclusão social. In: FÓRUM NACIONAL 2004. Rio de Janeiro: José Olympio, 2004. p. 185-224.

BAHIA, L.D.; ARBACHE, J. Diferenciação salarial segundo critérios de desempenho das empresas industriais brasileiras. In: SALERNO, M.S.; DE NEGRI, J.A. (Coord.). Inovação, padrões tecnológicos e desempenho das firmas industriais brasileiras. Brasília: Ipea, 2005. No prelo.

DE NEGRI, J.A.; ARBACHE J.; FALCÃO SILVA, M.L. A formação da Alca e seu impacto no potencial exportador brasileiro para os mercados dos Estados Unidos e do Canadá. Brasília, Ipea, 2003. (Texto para discussão, n. 991).

DE NEGRI, J.A.; ARBACHE J. O impacto de um acordo entre o Mercosul e a União Européia sobre o potencial exportador brasileiro para o mercado europeu. Brasília, Ipea, 2003. (Texto para discussão, n. 990).

DE NEGRI, J.A.; FREITAS, F. Inovação tecnológica, eficiência de escala e exportações brasileiras. Brasília, Ipea, 2004. (Texto para discussão, n. 1044).

DE NEGRI, J.A.; SALERNO, M.S.; CASTRO, A.B. Inovação, padrões tecnológicos e desempenho das firmas industriais brasileiras. In: SALERNO, M.S.; DE NEGRI, J.A. (Coord.). Inovação, padrões tecnológicos e desempenho das firmas industriais brasileiras. Brasília: Ipea, 2005. No prelo.

PORTER, M. Competitive strategy: techniques for analyzing industries and competitors. New York, The Free Press, 1980.

SALERNO, M.S.; DE NEGRI, J.A. (Coord.). Inovação, padrões tecnológicos e desempenho das firmas industriais brasileiras. Brasília: Ipea, 2005. No prelo.

Glauco Arbix: Professor do Departamento de Sociologia da USP e Presidente do Ipea.

João Alberto De Negri: Pesquisador e Diretor Adjunto de Estudos Setoriais do Ipea.

Artigo recebido em 5 de abril de 2005. Aprovado em 6 de maio de 2005. 